\title{
Spontaneous Passivation of Hybrid Perovskite by Sodium Ions from Glass Substrates: Mysterious Enhancement of Device Efficiency Revealed
}

\author{
Cheng Bi, ${ }^{\dagger}$ Xiaopeng Zheng, ${ }^{\dagger}$ Bo Chen, ${ }^{\dagger}$ Haotong Wei, ${ }^{\dagger}$ and Jinsong Huang ${ }^{*},,^{\dagger}+0$ \\ ${ }^{\dagger}$ Department of Mechanical and Materials Engineering and Nebraska Center for Materials and Nanoscience, University of \\ Nebraska-Lincoln, Lincoln, Nebraska 68588-0656, United States \\ ${ }^{\ddagger}$ Department of Applied Physical Sciences, University of North Carolina, Chapel Hill, North Carolina 27599, United States
}

ABSTRACT: The efficiency of a solar cell generally decreases over time due to degradation of the devices. Here we report a spontaneous increase of device efficiency for organic-inorganic hybrid perovskite (OIHP) solar cells after a period of storage that is speculated to be related to the sodium ions $\left(\mathrm{Na}^{+}\right)$diffused from the substrate. The efficiency of a $p-i-n$ planar heterojunction structure device rises from 18.8 to $20.2 \%$ after $24 \mathrm{~h}$ of storage in nitrogen. The increased efficiency can be explained by the prolonged carrier lifetime and reduced trap density in the OIHP
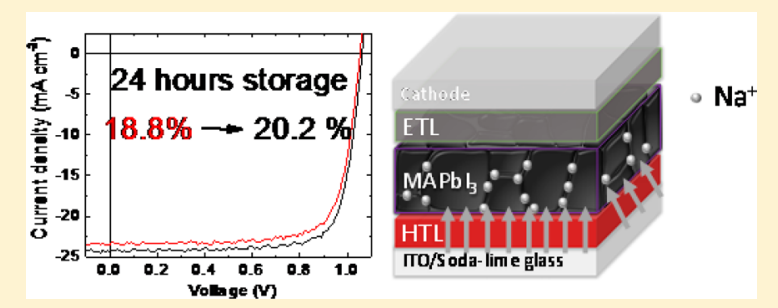
films. The expected contribution by $\mathrm{Na}^{+}$in defect passivation has been evidenced by studying the evolution of the film's photoluminescence (PL) lifetime, trap density, and device efficiency over storage duration on varied substrates that either contain $\mathrm{Na}^{+}$or do not. The passivation effect of $\mathrm{Na}^{+}$is further identified by the improved PL lifetime observed in the OIHP film made on a silicon substrate with intentionally added $\mathrm{Na}^{+}$.

$\mathrm{R}$ ecent important progress in enhancing the power conversion efficiency (PCE) of organic-inorganic hybrid perovskite (OIHP) solar cells counts on careful optimization of the precursor composition, ${ }^{1-6}$ device structure, $^{2,7,8}$ quality of OIHP films, ${ }^{1,6,7,9}$ as well as passivation of defects. $^{2,10-12}$ Like any type of solar cells, the efficiency of the OIHP solar cells is limited by charge recombination. While spectroscopic studies revealed that the dominating charge recombination mechanism at the working conditions of OIHP solar cells is bimolecular charge recombination, ${ }^{13}$ the presence of deep charge traps in polycrystalline OIHP films has been broadly observed, ${ }^{10,14}$ which inevitably causes charge recombination and loss of PCE. Many efforts have been made to suppress charge recombination by reducing the amount of deep traps. For example, the nonstoichiometric precursor ratio with a slight excess of methylammonium iodide (MAI) or $\mathrm{PbI}_{2}$ has been proposed to suppress nonradiative charge recombination at OIHP grain boundaries (GBs) or to passivate the surface of a $\mathrm{TiO}_{2}$ electron transport layer (ETL). ${ }^{4,5,15-17}$ Various techniques such as thermal engineering, solvent annealing, and nonwetting surfaces were believed to reduce the trap density by improving the crystallinity of OIHP films, enlarging crystalline grains, and reducing total GB area. ${ }^{1,9,18,19}$ One of the most broadly applied and simplest methods to passivate the surface of perovskite films is to use a fullerene and its derivatives, which are also good ETLs, though a passivation molecule does not necessarily need to be a charge transport material, $2,10,11,20$ resulting in both higher PCE and significantly reduced or eliminated photocurrent hysteresis at room temperature. The Lewis bases thiophene and pyridine were reported to form a coordinate or dative covalent bond with undercoordinated $\mathrm{Pb}$ ions at GBs and the surface. ${ }^{12}$ Their passivation effects were evidenced by the recovery of photoluminescence (PL) of the films. ${ }^{21}$ However, the devices treated by thiophene or pyridine still showed relatively low efficiency and notable photocurrent hysteresis. Physical absorption or chemical bonding of oxygen at the surface of methylammonium lead bromide $\left(\mathrm{MAPbBr}_{3}\right)$ single crystals was found to dramatically enhance the PL intensity and $\mathrm{PL}$ lifetime of $\mathrm{MAPbBr}_{3}$ single crystals as well as thin films. ${ }^{22,23}$ Similar PL intensity and lifetime enhancement of $\mathrm{O}_{2}$ is also observed in another perovskite methylammonium lead iodide $\left(\mathrm{MAPbI}_{3}\right){ }^{24,25}$ However, it is not clear yet whether the interaction of $\mathrm{MAPbI}_{3}$ with $\mathrm{O}_{2}$ indeed enhances device efficiency, while an overdose of oxygen has been broadly

Received: April 27, 2017

Accepted: May 15, 2017

Published: May 15, 2017 
reported to cause degradation of $\mathrm{MAPbI}_{3} \cdot{ }^{26,27}$ There is still large space to explore new passivation techniques to further increase OIHP device efficiency.

A miracle passivation species in copper indium gallium selenide (CIGS) thin film solar cells resulting in spontaneous efficiency enhancement are the alkaline metal ions that gradually diffuse from the underneath soda lime glass (SLG) during device fabrication or after device operation. ${ }^{28-31}$ Here, we report an observation of similar spontaneous improvement in OIHP device efficiency that may also associate with a selfpassivation effect at the perovskite GBs during device storage. The best-performing device shows an increased PCE of $20.2 \%$ after storage from an original efficiency of $18.8 \%$. Detailed analysis discovers that the sodium ions $\left(\mathrm{Na}^{+}\right)$coming from the indium tin oxide (ITO) glass substrates are responsible for the spontaneous passivation effect. On the other hand, the sodium salts, such as $\mathrm{NaI}$, though reported to enhance perovskite thin film morphology previously, ${ }^{32}$ are rarely observed to have a passivation effect that improves the optoelectronic properties.

The device structure is shown in Figure 1a, which presents a typical planar heterojunction (PHJ) structure with mixed-cation OIHP films as absorber layers and poly(bis(4-phenyl)(2,4,6trimethylphenyl)amine) (PTAA) and double fullerene layers as the hole transport layer (HTL) and ETL, respectively. The copper electrode was employed to minimize possible degradation between the perovskite layer and the cathode. ${ }^{33}$ For the mixed-cation perovskite film, methylammonium bromide (MABr, 10 wt \%) was blended with formamidinium iodide (FAI) solution in a two-step OIHP film fabrication process to stabilize the perovskite phase at room temperature and ambient condition. ${ }^{6}$ It also helps to obtain a "black" perovskite phase at the relatively lower annealing temperature of $100{ }^{\circ} \mathrm{C}$ rather than at the phase transformation temperature of $165{ }^{\circ} \mathrm{C}$ due to the better tolerance factor. ${ }^{34}$ Photocurrent hysteresis was minimized in our devices, as shown in Figure S1, due to high-quality and uniform perovskite films formed on nonwetting PTAA surfaces and the passivation of perovskite by the double fullerene layers. ${ }^{9,10}$ The fabricated devices were stored at either ambient or inert conditions $\left(\mathrm{N}_{2}\right.$ atmosphere $)$ with constant exposure to room light. Interestingly, the devices stored under both conditions showed an obvious increase of the PCE after storage for 2-3 days, with variation of the PCE summarized in Figure 1b,c. The initial PCE of the devices is already high, with an average PCE of $18.0 \%$. The average PCEs were improved by 3 and $8 \%$ for devices stored in ambient and inert conditions, respectively, among eight devices that come from the same batch tested at each condition. The PCE improvement mainly came from the increased short-circuit current $\left(J_{\mathrm{SC}}\right)$ and fill factor $(\mathrm{FF})$, as summarized in Figure S2, which shows the evolution of device performance parameters over time. This behavior is however different from what was observed in CIGS solar cells, where the PCE enhancement mainly came from the open-circuit voltage $\left(V_{\mathrm{OC}}\right)$ and $\mathrm{FF}$ enhancement. It is possible that the main limitation of $V_{\mathrm{OC}}$ in our device is energy disorder or energy level misalignment from interfacial/charge transport layers rather than the trap states at GBs and the surface, which have been passivated by double fullerene layers to a considerable extent. It is not surprising that devices stored in ambient conditions experienced a smaller increase of PCE, and some of them had a slightly declined efficiency after 1 week of storage because the devices also degraded in air. Clearly, the air exposure-induced degradation traded off with the spontaneous PCE improvement, and one
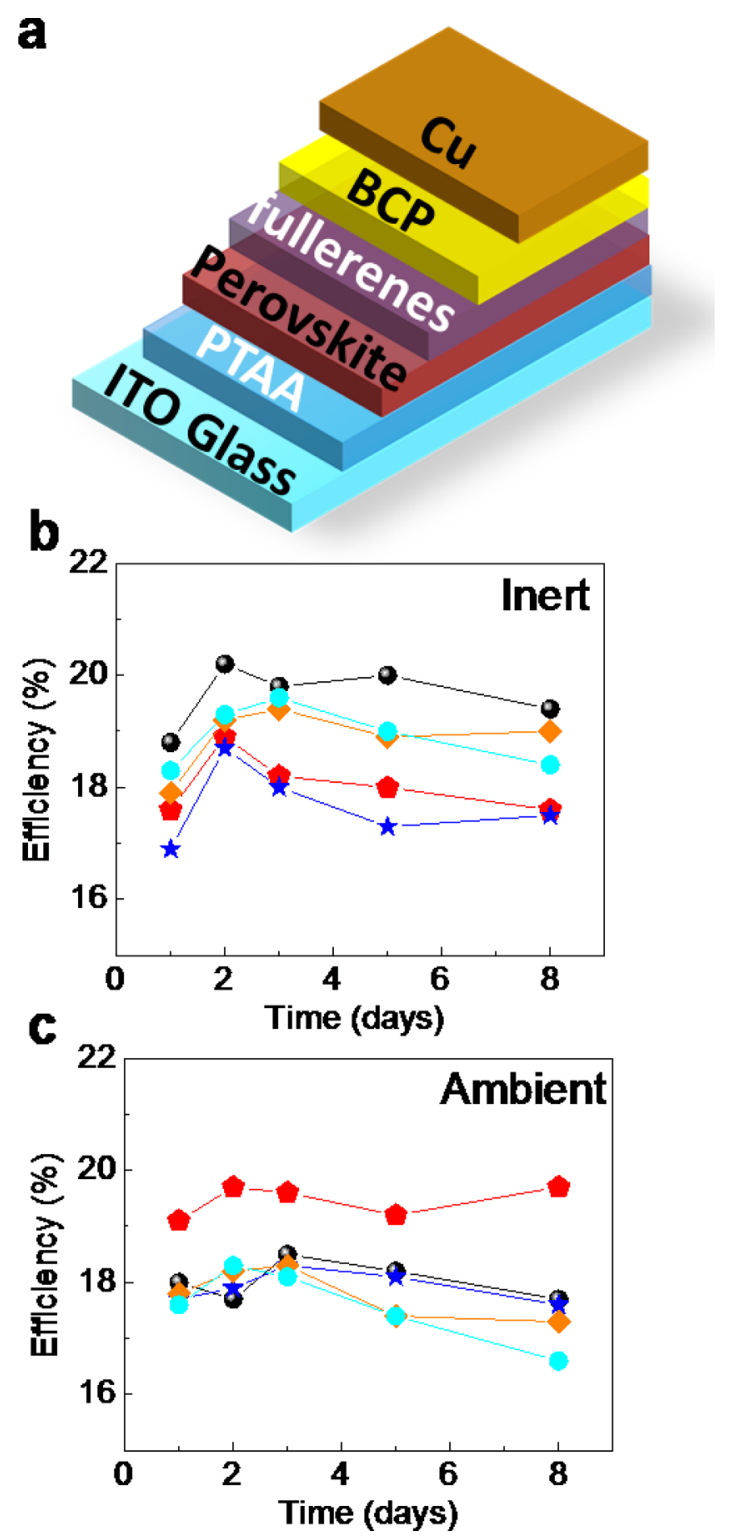

Figure 1. (a) Device structure scheme of the mixed-cation OIHP solar cell. PCE evolution of devices stored in (b) inert $\left(\mathrm{N}_{2}\right)$ and (c) ambient conditions. Each curve represents the PCE evolution of individual devices.

would only see the efficiency enhancement if the degradation of the device is relatively slow enough. Figure S2 shows that the decrease of device efficiency under ambient conditions is mainly due to reduction of the FF. The best-performing devices had a similar evolution trend with the average behavior. The largest PCE improvement reached 0.5 and $1.5 \%$ for the devices stored in ambient and inert conditions, respectively, as presented in Figure 1b,c.

The highest PCE of the OIHP devices was obtained with an initial PCE of $18.8 \%, V_{\mathrm{OC}}$ of $1.05 \mathrm{~V}$, FF of 0.763 , and $J_{\mathrm{SC}}$ of 23.5 $\mathrm{mA} \mathrm{cm}{ }^{-2}$. After storage in a $\mathrm{N}_{2}$ atmosphere for $24 \mathrm{~h}$, the PCE increased to $20.2 \%$, with $V_{\mathrm{OC}}$ of $1.06 \mathrm{~V}$, FF of 0.780 , and $J_{\mathrm{SC}}$ of $24.4 \mathrm{~mA} \mathrm{~cm}^{-2}$, as shown in Figure $2 \mathrm{a}$. The photocurrent of the devices stored for $24 \mathrm{~h}$ stabilized at $23.1 \mathrm{~mA} \mathrm{~cm}^{-2}$, measured at $0.86 \mathrm{~V}$ bias under constant illumination, yielding a stabilized PCE of $19.9 \%$, as shown in Figure $2 \mathrm{~b}$. That is very close to the PCE obtained from $J-V$ curve. The calculated $J_{S C}$ from external quantum efficiency (EQE) in Figure 2c increased from 23.4 to 


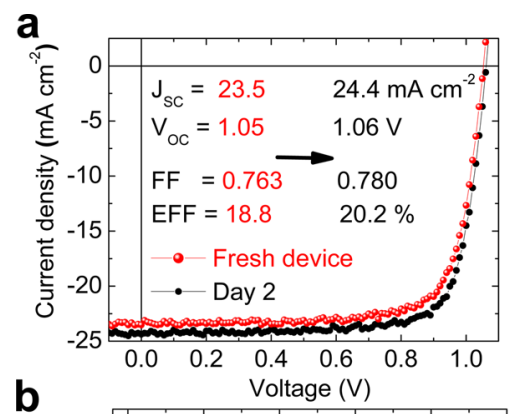

b
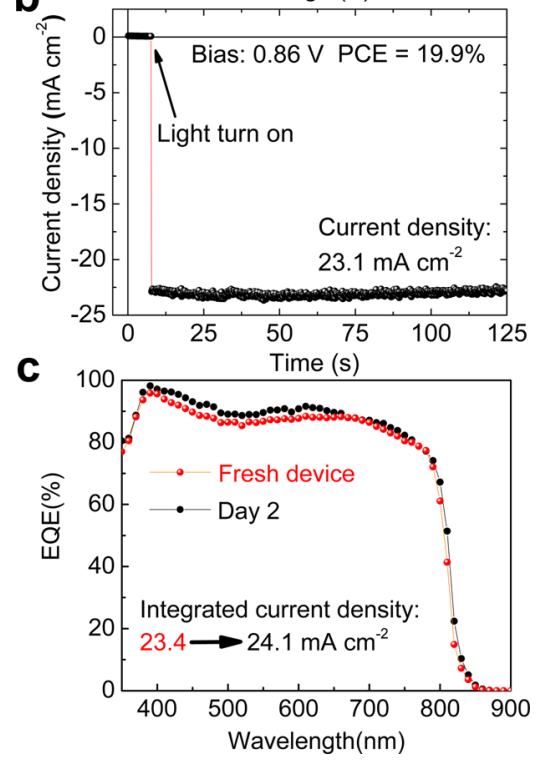

Figure 2. (a) $J-V$ curve and (c) EQE evolution of the bestperforming mixed-cation OIHP device at day 1 and day 2. (b) Stabilized photocurrent measurement of the device at $0.86 \mathrm{~V}$ bias under 1 Sun illumination.

$24.1 \mathrm{~mA} \mathrm{~cm}{ }^{-2}$, which agreed well with the measured photocurrent. It is noted that the increased photocurrent mainly came from the enhanced EQE in the wavelength range between 400 and $650 \mathrm{~nm}$. The increase of the EQE in a relatively shorter wavelength region should be attributed to better collection of carriers generated. ${ }^{1,9}$ The charges generated by shorter-wavelength light are mainly located close to the ITO glass side due to the shorter light penetration depth. Then, the increased $\mathrm{EQE}$ at the relatively short wavelength region indicates reduced charge recombination on the perovskite films close to the ITO substrate side. The change of the perovskite/PTAA interface or PTAA HTL during storage is excluded because it would otherwise change the device EQE at any wavelength.

Detailed analysis of device efficiency variation over time concludes that the $V_{\mathrm{OC}}$ and $\mathrm{FF}$ also increased over time during storage. We speculate that the efficiency improvement observed here is associated with reduced charge recombination in the perovskite films because the absorption of the films did not show obvious change over time. To investigate the origin of reduced charge recombination in the perovskite films close to the ITO side, thermal admittance spectroscopy (TAS) measurement was performed to evaluate the evolution of the trap density of states (tDOS) in the devices stored in ambient and inert atmospheres. As shown in Figure 3a,b, the measured trap densities in both sets of devices were reduced by $30-75 \%$ at the shallow trap region between 0.30 and $0.40 \mathrm{eV}$ after
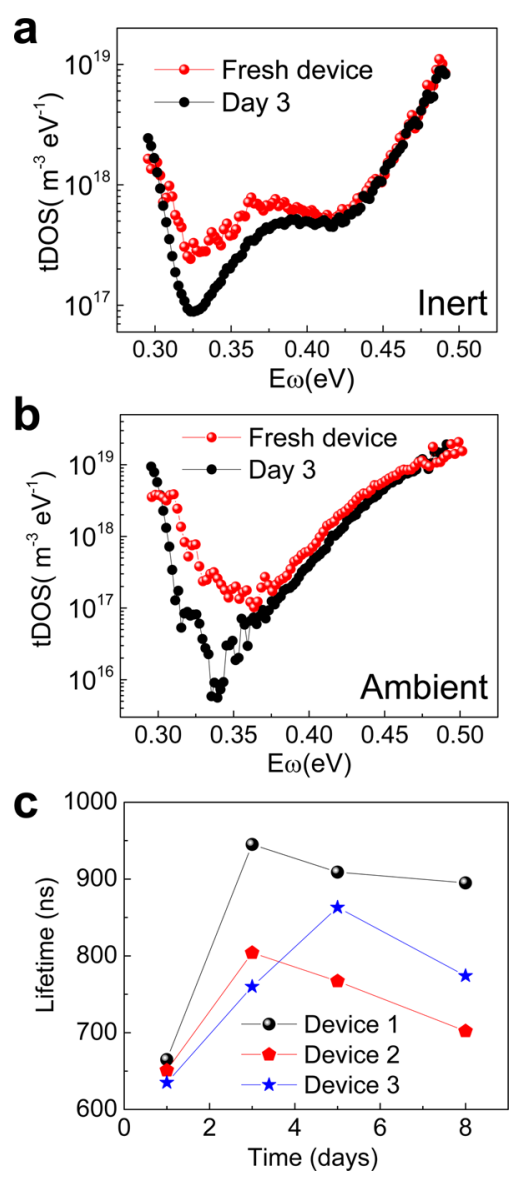

Figure 3. tDOS evolution of the devices stored at (a) inert and (b) ambient condition. (c) Carrier lifetime evolution of the devices stored at inert conditions. The lifetime was derived from TPV measurement.

storage for 3 days, while the traps in the deeper region showed no obvious change. Our previous studies indicate that the shallow traps are mainly located at the GBs of the polycrystalline OIHP films, ${ }^{9,10}$ and it is reasonable to infer the reduction of the tDOS at GBs of the polycrystalline films as the origin of the improved device PCE. The reduction of charge recombination in the devices is further evidenced by the increased carrier lifetime measured by the transient photovoltage (TPV) effect for the devices under 1 Sun illumination. The carrier lifetime evolution of the devices stored in $\mathrm{N}_{2}$ shown in Figure 3c experienced a significant increase by $25-45 \%$ in the first several days, correlating well with the observed spontaneous reduction of the tDOS at the GBs. The longest TPV lifetime reached $945 \mathrm{~ns}$, obtained from a device stored in $\mathrm{N}_{2}$ for $48 \mathrm{~h}$, as shown in Figure S4, which is also 50\% longer compared with that from our previous $\mathrm{MAPbI}_{3}$ devices, ${ }^{35}$ again indicating the significant reduction of trap states during storage. The carrier recombination lifetime variation trend is consistent with the trap density change over time, indicating that the nonnegligible trap states did cause carrier recombination even in the optimized thin film PVs. This is consistent with our previous analysis concluding that charge recombination at the interfaces and GBs in the devices even with optimized fabrication conditions was at least 10 times faster than that in the grain interior. ${ }^{10}$ It also shows a large potential to further increase the device efficiency by defect passivation. 

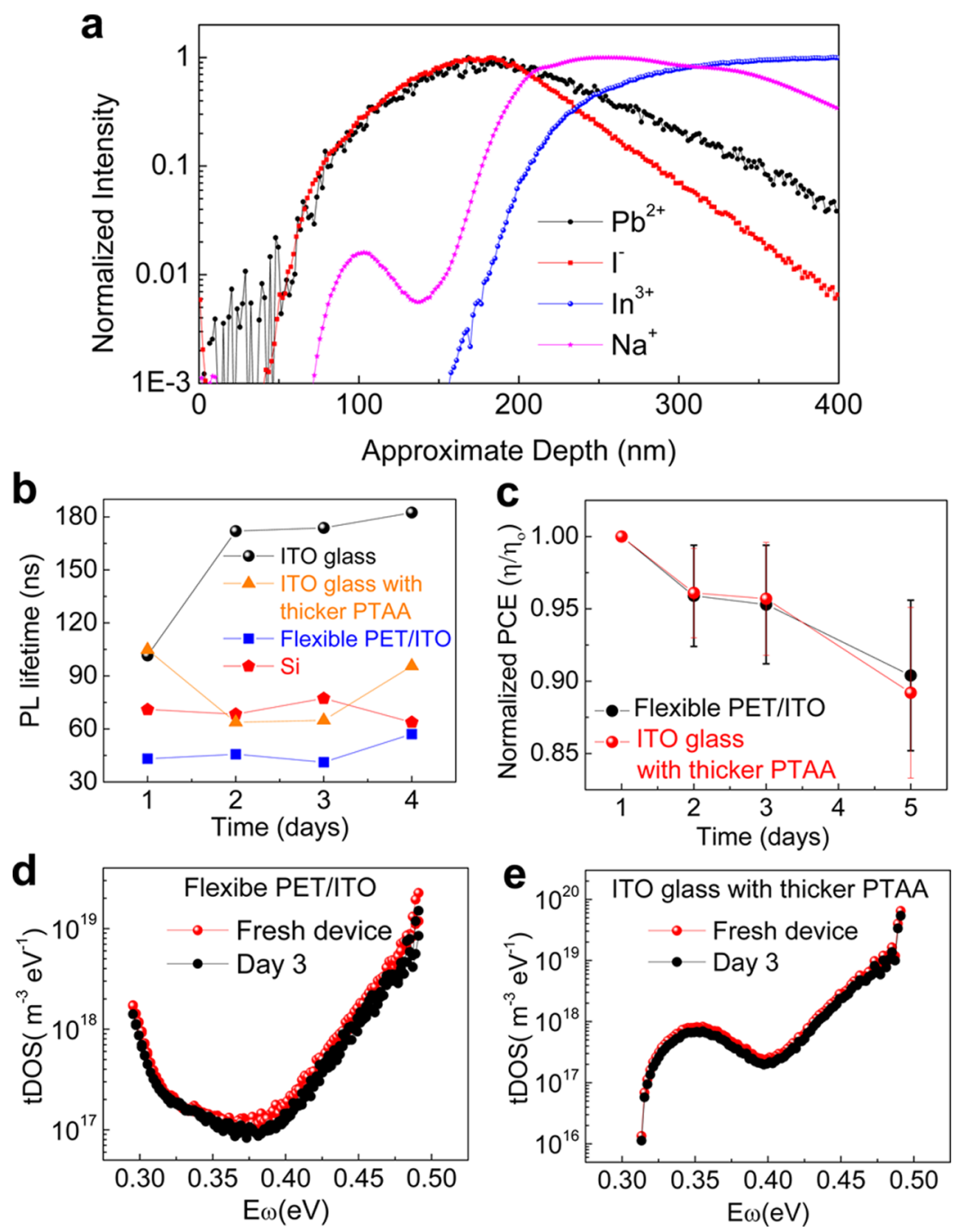

Figure 4. (a) SIMS measurement of interdiffusion-grown MAPbI ${ }_{3}$ films on an ITO glass substrate. (b) Carrier PL lifetime of the mixed-cation OIHP films grown on varied substrates ranging from ITO glass, Si, flexible PET/ITO, and ITO glass coated with thicker PTAA. The carrier PL lifetime was derived from TRPL measurement. All of the substrates were coated with a hydrophobic PTAA layer to ensure that the morphologies of the top perovskite films were similar. (c) PCE evolution of the devices on flexible PET/ITO and ITO glass with thicker PTAA. tDOS evolution of the devices on (d) flexible PET/ITO and (e) ITO glass with thicker PTAA.

It is interesting and important to find out what improved the PCE of the devices spontaneously. Such spontaneous improvement of the PCE is likely to be attributed by enhancement of the OIHP layer rather than interface or charge transport layers because we have already observed prolonged carrier lifetime, which was associated with the reduced trap density in GBs of OIHP films. There have been related observations of spontaneous enhancement of the PL lifetime in OIHP films, though there was not a related device performance study. It was attributed to further reaction of the residue precursors or healing of defects by oxygen/moisture. ${ }^{36,37}$ However, these mechanisms cannot explain the phenomenon observed here because a higher annealing temperature of $100{ }^{\circ} \mathrm{C}$ used here makes it unlikely to have unreacted precursors. In addition, further increased annealing time or temperature should remove any precursor residues, but in many cases, further increased annealing made the device performance even worse. The impact of environmental vapor can be also excluded because our devices showed improved PCE in both inert and ambient conditions. Besides, the change of perovskite morphology can be excluded. Ostwald ripening or grain coalescence usually require both high-temperature postsynthesis heating treatment and an additional organic precursor such as MAI and MABr, and therefore, it is less likely to happen at inert conditions and room temperature without excess precursors, which is confirmed by no observed change in the perovskite crystalline orientation and crystallinity after 1 week of storage in a $\mathrm{N}_{2}$ atmosphere measured by X-ray diffraction (XRD) and a scanning electron microscope (Figure S3). The absence of a $\mathrm{PbI}_{2}$ peak in the XRD pattern also excludes defect passivation from excess $\mathrm{PbI}_{2}$ in our case. On the other hand, we cannot totally rule out the possibility of room-temperature annealing of the perovskite thin film, which may result in chemical change at the surface/GB or very small Ostwald ripening that is difficult to observe from topography measurements.

With all of the possible reasons for the spontaneous improvement, alkaline metal ions like $\mathrm{Na}^{+}$from the underneath ITO glass are most likely to be taken into account. One piece of evidence is the observed presence of a certain concentration of $\mathrm{Na}^{+}$in the interdiffusion-grown $\mathrm{MAPbI}_{3}$ films on ITO glass by secondary ion mass spectrometry (SIMS) measurements, as shown in Figure 4a, where $\mathrm{Pb}^{2+} / \mathrm{I}^{-}$and $\mathrm{In}^{3+}$ come from the 
perovskite layer and the underneath ITO layer, respectively. That probably resulted from $\mathrm{Na}^{+}$diffusion from ITO glass during thermal annealing and sample storage. Given that we observed reduction of tDOS at GBs during sample storage, it is reasonable to speculate that alkaline metal ions from ITO glass have some correlations with the observation here. The passivation effect of alkaline metal ions on GBs has been well established in CIGS solar cells. It was shown that $\mathrm{Na}^{+}$from the SLG diffused through a Mo back contact electrode into the CIGS films during the film fabrication process and/or storage/ operation for several days. ${ }^{29,30}$

To verify the possible contribution from the ITO glass substrates, time-resolved photoluminescence (TRPL) measurement was performed on the mixed-cation OIHP films grown on varied substrates including regular ITO glass, $\mathrm{Si}$, a flexible polyethylene terephthalate (PET)/ITO substrate, and regular ITO glass coated with a thicker PTAA layer $(80 \mathrm{~nm})$. It should be noted that the optimized thickness of PTAA in a highefficiency device is only 5-20 $\mathrm{nm}$. Here, a thicker PTAA layer on top of ITO glass is expected to block or slow down $\mathrm{Na}^{+}$ diffusion from underneath of SLG to the perovskite films, while $\mathrm{Si}$ and flexible PET substrates have a negligible amount of $\mathrm{Na}^{+}$. All other substrates were covered with PTAA layers so that the OIHP films had a similar morphology as that in regular devices. TRPL results in Figure $4 \mathrm{~b}$ show that the PL lifetime of the perovskite films grown on an ITO glass substrate increased by almost $80 \%$ from 102 to 182 ns after $72 \mathrm{~h}$ of storage in $\mathrm{N}_{2}$. The increased PL lifetime is well correlated with the reduction of trap states. In contrast, the PL lifetime of the perovskite films grown on other substrates remained almost unchanged during storage of the same duration. Given that the bulk of the perovskite grains has a limited amount of deep trap states due to the high crystallinity and special defect physics, ${ }^{38}$ which was evidenced by the very long diffusion length measured in the single crystal due to the nature of this type of materials, ${ }^{39}$ the prolonged lifetime observed here could be attributed to healing of charge traps at GBs due to $\mathrm{Na}^{+}$diffusion during storage. Another point worth mentioning is that the initial PL lifetime on the ITO sample is longer than that of other samples by $1-3$ fold. We infer that certain amounts of $\mathrm{Na}^{+}$have already diffused from underneath of the ITO glass substrate during the thermal annealing process. To further investigate the passivation effect from substrates, the devices on flexible PET/ITO and ITO glass with thicker PTAA were fabricated to check the PCE evolution during storage. It is not surprising that the PCEs of both sets of devices decreased in a very similar manner, as shown in Figure 4c, probably because the GBs received no passivation effect from the substrates. The tDOS evolution in Figure 4d,e further confirmed this scenario that no significant change was observed in the two sets of devices during the 3 day storage, which is a different observation from that of the devices made on regular ITO glass. The evolution of device efficiency and tDOS shown here proves that the spontaneous enhancement should be attributed to the glass substrates, rather than the interface enhancement, such as oxidation and self-doping of the OIHP film to charge transport layers. Otherwise, similar enhancement of PCE and reduction of tDOS are expected in the $\mathrm{N}_{2}$-stored flexible device with the same carrier transport layers but PET/ITO substrate, whose PCE and tDOS are shown in Figure 4c,d.

To further prove the passivation effect of $\mathrm{Na}^{+}$on the perovskite GBs, we intentionally added some $\mathrm{Na}^{+}$on the $\mathrm{Si}$ substrates to observe whether it would impact the PL lifetime of the perovskite films deposited on them. As shown in Figure $5 \mathrm{a}$, we spin-coated $\mathrm{NaCl}$ solution with concentrations of 0.1
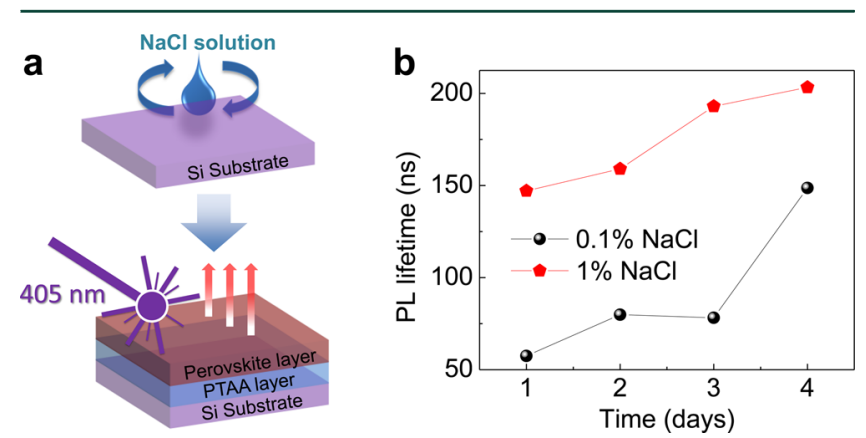

Figure 5. Illustration of intentionally adding a $\mathrm{Na}^{+}$source on a $\mathrm{Si}$ substrate and the following TRPL measurement. (b) Carrier PL lifetime of the mixed-cation OIHP films with an intentionally added $\mathrm{Na}^{+}$source from 0.1 and $1 \mathrm{wt} \% \mathrm{NaCl}$ solutions.

and 1 wt \% onto the Si substrates, which was followed by deposition of the thin PTAA $(5-20 \mathrm{~nm})$ and perovskite layers with exactly the same procedure as that previously used to make the thickness and morphology of the perovskite films be similar to that of previous samples. The films were stored in a $\mathrm{N}_{2}$ atmosphere, and the PL lifetime was monitored. The PL lifetime of these films shown in Figure $5 b$ showed an increase by 30 and $100 \%$ to 212 and 150 ns for the perovskite films with 1 and $0.1 \mathrm{wt} \% \mathrm{NaCl}$-treated $\mathrm{Si}$ substrates, respectively, after storage for $72 \mathrm{~h}$. In striking contrast, almost no change of the PL lifetime was observed from the perovskite film with an untreated Si substrate, as in Figure 4a. The results shown here indicate gradual diffusion of $\mathrm{Na}^{+}$to perovskite films and their passivation effect. A longer initial PL lifetime of around $150 \mathrm{~ns}$ was observed for the perovskite film on the Si substrate treated with a higher concentration of $\mathrm{NaCl}$. Again, we speculate that a larger amount of $\mathrm{Na}^{+}$or $\mathrm{Cl}^{-}$may already diffuse into GBs to passivate the trap states during the thermal annealing of perovskite films. Here, we cannot exclude the possibility that $\mathrm{Cl}^{-}$might contribute to the higher original PL lifetime. Incorporation of $\mathrm{Cl}^{-}$was found to improve the device efficiency and was believed to have a passivation effect on the perovskite films, though it was preferentially located close to the interface of the perovskite and carrier transport layers. ${ }^{40-42}$

One possible pathway of the $\mathrm{Na}^{+}$passivation is to substitute the $\mathrm{MA}^{+}$vacancies that most likely occur in OIHP polycrystalline thin films due to the volatile nature of the organic component. In this context, many other types of monovalent cations should have a similar passivation effect. This speculation is partially supported by some recent observations. Monovalent cations including $\mathrm{Cu}^{+}$were found to reduce the Urbach energy. ${ }^{43}$ Recent study of $\mathrm{Cs}^{+}$-and $\mathrm{Rb}^{+}$-containing perovskite solar cells showed that they have better thermal stability as well as better device efficiency, which were attributed to better material stability with a more appropriate tolerance factor and less volatile organic cations. ${ }^{44-47}$ However, the observation of a smaller Urbach tail of the $\mathrm{Cs}^{+}$-containing perovskite also raises a question whether $\mathrm{Cs}^{+}$has a similar passivation effect as that reported here, which is still in our current study.

In summary, a spontaneous increase of device PCE associated with the reduction of tDOS at the GBs of perovskite films was observed during the storage of them in both ambient and inert conditions. $\mathrm{Na}^{+}$ions are expected to contribute to this PCE improvement by a passivation effect on the GBs with the 
diffusion of $\mathrm{Na}^{+}$from the underneath ITO glass substrate during film fabrication and storage. Currently, very limited research probes the possible passivation effect of alkaline metal ions in perovskite solar cells. This work reveals a possible passivation function from the Na-containing SLG substrates for perovskite solar cells and paves the way for further study of the passivation technique by using the right amount of monovalent ions. This passivation technique can potentially find applications in other optoelectronic devices that require longer carrier lifetime and lower traps density, such as ultrafast and low-noise detectors, low-threshold lasers, and lower-driving voltage lightemitting diodes.

\section{ASSOCIATED CONTENT}

\section{Supporting Information}

The Supporting Information is available free of charge on the ACS Publications website at DOI: 10.1021/acsenergylett.7b00356.

Experimental method, the device's $J-V$ curve with different scanning direction (Figure S1), the evolution of the device's $J_{\mathrm{SC}}, V_{\mathrm{OC}}$, and FF during storage (Figure S2), XRD pattern and SEM image of of the perovskite film before and after storage (Figure S3), and the photovoltage decay of a stored device (Figure S4) (PDF)

\section{AUTHOR INFORMATION}

\section{Corresponding Author}

*E-mail: jhuang2@unl.edu.

\section{ORCID}

Jinsong Huang: 0000-0002-0509-8778

\section{Notes}

The authors declare no competing financial interest.

E-mail: cheng.bi@huskers.unl.edu (C.B.); xpzheng@huskers. unl.edu (X.Z.); bochen@unl.edu (B.C.); hwei@unl.edu (H.W.).

\section{ACKNOWLEDGMENTS}

This work was supported in part by the Air Force Office of Scientific Research (AFOSR) (Grant No. A9550-16-1-0299), the Office of Naval Research (ONR) (Grant No. N00014-17-12163), and the National Science Foundation (NSF) (Grant No. ECCS-1252623).

\section{REFERENCES}

(1) Xiao, Z.; Dong, Q.; Bi, C.; Shao, Y.; Yuan, Y.; Huang, J. Solvent Annealing of Perovskite-Induced Crystal Growth for PhotovoltaicDevice Efficiency Enhancement. Adv. Mater. 2014, 26, 6503-6509.

(2) Xiao, Z.; Bi, C.; Shao, Y.; Dong, Q.; Wang, Q.; Yuan, Y.; Wang, C.; Gao, Y.; Huang, J. Efficient, High Yield Perovskite Photovoltaic Devices Grown by Interdiffusion of Solution-Processed Precursor Stacking Layers. Energy Environ. Sci. 2014, 7, 2619-2623.

(3) Bi, C.; Shao, Y.; Yuan, Y.; Xiao, Z.; Wang, C.; Gao, Y.; Huang, J. Understanding the Formation and Evolution of Interdiffusion Grown Organolead Halide Perovskite Thin Films by Thermal Annealing. J. Mater. Chem. A 2014, 2, 18508-18514.

(4) Son, D.-Y.; Lee, J.-W.; Choi, Y. J.; Jang, I.-H.; Lee, S.; Yoo, P. J.; Shin, H.; Ahn, N.; Choi, M.; Kim, D.; et al. Self-Formed Grain Boundary Healing Layer for Highly Efficient $\mathrm{CH}_{3} \mathrm{NH}_{3} \mathrm{PbI}_{3}$ Perovskite Solar Cells. Nature Energy 2016, 1, 16081.

(5) Bi, D.; Tress, W.; Dar, M. I.; Gao, P.; Luo, J.; Renevier, C.; Schenk, K.; Abate, A.; Giordano, F.; Correa Baena, J.-P.; et al. A. Efficient Luminescent Solar Cells Based on Tailored Mixed-Cation Perovskites. Sci. Adv. 2016, 2, e1501170.
(6) Yang, W. S.; Noh, J. H.; Jeon, N. J.; Kim, Y. C.; Ryu, S.; Seo, J.; Seok, S. I. High-Performance Photovoltaic Perovskite Layers Fabricated Through Intramolecular Exchange. Science 2015, 348, 1234-1237.

(7) Liu, M.; Johnston, M. B.; Snaith, H. J. Efficient Planar Heterojunction Perovskite Solar Cells by Vapour Deposition. Nature 2013, 501, 395-398.

(8) Burschka, J.; Pellet, N.; Moon, S.-J.; Humphry-Baker, R.; Gao, P.; Nazeeruddin, M. K.; Gratzel, M. Sequential Deposition as a Route to High-Performance Perovskite-Sensitized Solar Cells. Nature 2013, 499, 316-319.

(9) Bi, C.; Wang, Q.; Shao, Y.; Yuan, Y.; Xiao, Z.; Huang, J. Nonwetting Surface-driven High-aspect-ratio Crystalline Grain Growth for Efficient Hybrid Perovskite Solar Cells. Nat. Commun. 2015, 6, 7747.

(10) Shao, Y.; Xiao, Z.; Bi, C.; Yuan, Y.; Huang, J. Origin and Elimination of Photocurrent Hysteresis by Fullerene Passivation in $\mathrm{CH}_{3} \mathrm{NH}_{3} \mathrm{PbI}_{3}$ Planar Heterojunction Solar Cells. Nat. Commun. 2014, $5,5784$.

(11) Xu, J.; Buin, A.; Ip, A. H.; Li, W.; Voznyy, O.; Comin, R.; Yuan, M.; Jeon, S.; Ning, Z.; McDowell, J. J.; et al. Perovskite-Fullerene Hybrid Materials Suppress Hysteresis in Planar Diodes. Nat. Commun. 2015, 6, 7081.

(12) Noel, N. K.; Abate, A.; Stranks, S. D.; Parrott, E. S.; Burlakov, V. M.; Goriely, A.; Snaith, H. J. Enhanced Photoluminescence and Solar Cell Performance via Lewis Base Passivation of Organic-inorganic Lead Halide Perovskites. ACS Nano 2014, 8, 9815-9821.

(13) Johnston, M. B.; Herz, L. M. Hybrid Perovskites for Photovoltaics: Charge-Carrier Recombination, Siffusion, and Radiative Efficiencies. Acc. Chem. Res. 2016, 49, 146-154.

(14) Duan, H.-S.; Zhou, H.; Chen, Q.; Sun, P.; Luo, S.; Song, T.-B.; Bob, B.; Yang, Y. The Identification and Characterization of Defect States in Hybrid Organic-inorganic Perovskite Photovoltaics. Phys. Chem. Chem. Phys. 2015, 17, 112-116.

(15) Chen, Q.; Zhou, H.; Song, T.-B.; Luo, S.; Hong, Z.; Duan, H.-S.; Dou, L.; Liu, Y.; Yang, Y. Controllable Self-Induced Passivation of Hybrid Lead Iodide Perovskites Toward High Performance Solar Cells. Nano Lett. 2014, 14, 4158-4163.

(16) Zhang, T.; Guo, N.; Li, G.; Qian, X.; Zhao, Y. A Controllable Fabrication of Grain Boundary $\mathrm{PbI}_{2}$ Nanoplates Passivated Lead Halide Perovskites for High Performance Solar Cells. Nano Energy 2016, 26, 50-56.

(17) Kim, Y. C.; Jeon, N. J.; Noh, J. H.; Yang, W. S.; Seo, J.; Yun, J. S.; Ho-Baillie, A.; Huang, S.; Green, M. A.; Seidel, J.; et al. Beneficial Effects of $\mathrm{PbI}_{2}$ Incorporated in Organo-Lead Halide Perovskite Solar Cells. Adv. Energy Mater. 2016, 6, 1502104.

(18) Jeon, N. J.; Noh, J. H.; Kim, Y. C.; Yang, W. S.; Ryu, S.; Seok, S. I. Solvent Engineering for High-performance Inorganic-Organic Hybrid Perovskite Solar Cells. Nat. Mater. 2014, 13, 897-903.

(19) Xiao, M.; Huang, F.; Huang, W.; Dkhissi, Y.; Zhu, Y.; Etheridge, J.; Gray-Weale, A.; Bach, U.; Cheng, Y. B.; Spiccia, L. A Fast Deposition-Crystallization Procedure for Highly Efficient Lead Iodide Perovskite Thin-film Solar Cells. Angew. Chem. 2014, 126, 1005610061.

(20) Wojciechowski, K.; Stranks, S. D.; Abate, A.; Sadoughi, G.; Sadhanala, A.; Kopidakis, N.; Rumbles, G.; Li, C.-Z.; Friend, R. H.; Jen, A. K. Y.; et al. Heterojunction Modification for Highly Efficient Organic-Inorganic Perovskite Solar Cells. ACS Nano 2014, 8, 1270112709.

(21) de Quilettes, D. W.; Vorpahl, S. M.; Stranks, S. D.; Nagaoka, H.; Eperon, G. E.; Ziffer, M. E.; Snaith, H. J.; Ginger, D. S. Impact of Microstructure on Local Carrier Lifetime in Perovskite Solar Cells. Science 2015, 348, 683-686.

(22) Wei, H.; Fang, Y.; Mulligan, P.; Chuirazzi, W.; Fang, H.-H.; Wang, C.; Ecker, B. R.; Gao, Y.; Loi, M. A.; Cao, L.; et al. Sensitive Xray Detectors Made of Methylammonium Lead Tribromide Perovskite Single Crystals. Nat. Photonics 2016, 10, 333-339.

(23) Fang, H.-H.; Adjokatse, S.; Wei, H.; Yang, J.; Blake, G. R.; Huang, J.; Even, J.; Loi, M. A. Ultrahigh Sensitivity of Methyl- 
ammonium Lead Tribromide Perovskite Single Crystals to Environmental Gases. Sci. Adv. 2016, 2, e1600534.

(24) Tian, Y.; Peter, M.; Unger, E.; Abdellah, M.; Zheng, K.; Pullerits, T.; Yartsev, A.; Sundström, V.; Scheblykin, I. G. Mechanistic Insights into Perovskite Photoluminescence Enhancement: Light Curing with Oxygen Can Boost Yield Thousandfold. Phys. Chem. Chem. Phys. 2015, 17, 24978-24987.

(25) Galisteo-López, J. F.; Anaya, M.; Calvo, M. E.; Míguez, H. Environmental Effects on the Photophysics of Organic-Inorganic Halide Perovskites. J. Phys. Chem. Lett. 2015, 6, 2200-2205.

(26) Aristidou, N.; Sanchez-Molina, I.; Chotchuangchutchaval, T.; Brown, M.; Martinez, L.; Rath, T.; Haque, S. A. The Role of Oxygen in the Degradation of Methylammonium Lead Trihalide Perovskite Photoactive Layers. Angew. Chem., Int. Ed. 2015, 54, 8208-8212.

(27) Bryant, D.; Aristidou, N.; Pont, S.; Sanchez-Molina, I.; Chotchunangatchaval, T.; Wheeler, S.; Durrant, J. R.; Haque, S. A. Light and Oxygen Induced Degradation Limits the Operational Stability of Methylammonium Lead Triiodide Perovskite Solar Cells. Energy Environ. Sci. 2016, 9, 1655-1660.

(28) Kronik, L.; Cahen, D.; Schock, H. W. Effects of Sodium on Polycrystalline $\mathrm{Cu}(\mathrm{In}, \mathrm{Ga}) \mathrm{Se}_{2}$ and Its Solar Cell Performance. Adv. Mater. 1998, 10, 31-36.

(29) Heske, C.; Fink, R.; Umbach, E.; Riedl, W.; Karg, F. Na-induced Effects on the Electronic Structure and Composition of $\mathrm{Cu}(\mathrm{In}, \mathrm{Ga}) \mathrm{Se}_{2}$ Thin-Film Surfaces. Appl. Phys. Lett. 1996, 68, 3431-3433.

(30) Rudmann, D.; Da Cunha, A.; Kaelin, M.; Kurdesau, F.; Zogg, H.; Tiwari, A.; Bilger, G. Efficiency Enhancement of $\mathrm{Cu}(\mathrm{In}, \mathrm{Ga}) \mathrm{Se}_{2}$ Solar Cells Due to Post-deposition Na Incorporation. Appl. Phys. Lett. 2004, 84, 1129-1131.

(31) Chirilă, A.; Reinhard, P.; Pianezzi, F.; Bloesch, P.; Uhl, A. R.; Fella, C.; Kranz, L.; Keller, D.; Gretener, C.; Hagendorfer, H.; et al. Potassium-induced Surface Modification of $\mathrm{Cu}(\mathrm{In}, \mathrm{Ga}) \mathrm{Se}_{2}$ Thin Films for High-Efficiency Solar Cells. Nat. Mater. 2013, 12, 1107-1111.

(32) Bag, S.; Durstock, M. F. Large Perovskite Grain Growth in LowTemperature Solution-processed Planar p-i-n Solar Cells by Sodium Addition. ACS Appl. Mater. Interfaces 2016, 8, 5053-5057.

(33) Deng, Y.; Dong, Q.; Bi, C.; Yuan, Y.; Huang, J. Air-Stable, Efficient Mixed-Cation Perovskite Solar Cells with $\mathrm{Cu}$ Electrode by Scalable Fabrication of Active Layer. Adv. Energy Mater. 2016, 6, 1600372.

(34) Fu, Y.; Zhu, H.; Schrader, A. W.; Liang, D.; Ding, Q.; Joshi, P.; Hwang, L.; Zhu, X.; Jin, S. Nanowire Lasers of Formamidinium Lead Halide Perovskites and Their Stabilized Alloys with Improved Stability. Nano Lett. 2016, 16, 1000-1008.

(35) Shao, Y.; Yuan, Y.; Huang, J. Correlation of Energy Disorder and Open-circuit Voltage in Hybrid Perovskite Solar Cells. Nature Energy 2016, 1, 15001.

(36) Yamada, Y.; Endo, M.; Wakamiya, A.; Kanemitsu, Y. Spontaneous Defect Annihilation in $\mathrm{CH}_{3} \mathrm{NH}_{3} \mathrm{PbI}_{3}$ Thin Films at Room Temperature Revealed by Time-Resolved Photoluminescence Spectroscopy. J. Phys. Chem. Lett. 2015, 6, 482-486.

(37) Fang, H. H.; Wang, F.; Adjokatse, S.; Zhao, N.; Loi, M. A. Photoluminescence Enhancement in Formamidinium Lead Iodide Thin Films. Adv. Funct. Mater. 2016, 26, 4653-4659.

(38) Yin, W.-J.; Shi, T.; Yan, Y. Unusual Defect Physics in $\mathrm{CH}_{3} \mathrm{NH}_{3} \mathrm{PbI}_{3}$ Perovskite Solar Cell Absorber. Appl. Phys. Lett. 2014, 104, 063903.

(39) Dong, Q.; Fang, Y.; Shao, Y.; Mulligan, P.; Qiu, J.; Cao, L.; Huang, J. Electron-hole Diffusion Lengths $>175 \mu \mathrm{m}$ in SolutionGrown $\mathrm{CH}_{3} \mathrm{NH}_{3} \mathrm{PBI}_{3}$ Single Crystals. Science 2015, 347, 967-970.

(40) Starr, D. E.; Sadoughi, G.; Handick, E.; Wilks, R. G.; Alsmeier, J. H.; Köhler, L.; Gorgoi, M.; Snaith, H. J.; Bär, M. Direct Observation of an Inhomogeneous Chlorine Distribution in $\mathrm{CH}_{3} \mathrm{NH}_{3} \mathrm{PbI}_{3-\mathrm{x}} \mathrm{Cl}_{\mathrm{x}}$ Layers: Surface Depletion and Interface Enrichment. Energy Environ. Sci. 2015, $8,1609-1615$.

(41) Colella, S.; Mosconi, E.; Pellegrino, G.; Alberti, A.; Guerra, V. L.; Masi, S.; Listorti, A.; Rizzo, A.; Condorelli, G. G.; De Angelis, F.; et al. Elusive Presence of Chloride in Mixed Halide Perovskite Solar Cells. J. Phys. Chem. Lett. 2014, 5, 3532-3538.
(42) Mosconi, E.; Ronca, E.; De Angelis, F. First-principles Investigation of the $\mathrm{TiO}_{2} /$ Organohalide Perovskites Interface: The Role of Interfacial Chlorine. J. Phys. Chem. Lett. 2014, 5, 2619-2625.

(43) Abdi-Jalebi, M.; Dar, M. I.; Sadhanala, A.; Senanayak, S. P.; Franckevičius, M.; Arora, N.; Hu, Y.; Nazeeruddin, M. K.; Zakeeruddin, S. M.; Grätzel, M.; et al. Impact of Monovalent Cation Halide Additives on the Structural and Optoelectronic Properties of $\mathrm{CH}_{3} \mathrm{NH}_{3} \mathrm{PbI}_{3}$ Perovskite. Adv. Energy Mater. 2016, 6, 1502472.

(44) Lee, J. W.; Kim, D. H.; Kim, H. S.; Seo, S. W.; Cho, S. M.; Park, N. G. Formamidinium and Cesium Hybridization for Photo-and Moisture-Stable Perovskite Solar Cell. Adv. Energy Mater. 2015, 5, 1501310.

(45) Saliba, M.; Matsui, T.; Seo, J.-Y.; Domanski, K.; Correa-Baena, J.-P.; Nazeeruddin, M. K.; Zakeeruddin, S. M.; Tress, W.; Abate, A.; Hagfeldt, A.; et al. Cesium-Containing Triple Cation Perovskite Solar Cells: Improved Stability, Reproducibility and High Efficiency. Energy Environ. Sci. 2016, 9, 1989-1997.

(46) McMeekin, D. P.; Sadoughi, G.; Rehman, W.; Eperon, G. E.; Saliba, M.; Hörantner, M. T.; Haghighirad, A.; Sakai, N.; Korte, L.; Rech, B.; et al. A Mixed-Cation Lead Mixed-Halide Perovskite Absorber for Tandem Solar Cells. Science 2016, 351, 151-155.

(47) Saliba, M.; Matsui, T.; Domanski, K.; Seo, J.-Y.; Ummadisingu, A.; Zakeeruddin, S. M.; Correa-Baena, J.-P.; Tress, W. R.; Abate, A.; Hagfeldt, A.; et al. Incorporation of Rubidium Cations into Perovskite Solar Cells Improves Photovoltaic Performance. Science 2016, 354, 206-209. 